\title{
Fuera de foco: ironía y fotografía en Estrella distante, de Roberto Bolaño
}

\author{
Gonzalo Maier ${ }^{1}$
}

Published online: 14 September 2015

(C) The Author(s) 2015. This article is published with open access at Springerlink.com

\begin{abstract}
This article analyzes the photographs described in Roberto Bolaño's Estrella distante from the paradigm of irony. Either because they are lost, blurred or out of focus, the unreliability of the images implies that they cannot be used as witness of the violence of Carlos Wielder's acts, a poet-aviator who murders and holds an exhibition of photographs showing the victims in the 1970's. In fact, instead of acting as a memory archive, those images promote a constant forgetting and, as Paul de Man points out, forgetting is precisely the irony of memory. By examining photographs of brutally murdered twin sisters, a mysterious dictatorship agent, and the picture of a group of young poets, this article will explore how irony is used as a strategy to question the discourses on memory in the context of the postdictatorship in Chile. Furthermore, the irony's edge of the photographs will be examined in relation to the ways in which violence is portrayed and how influences what is remembered.
\end{abstract}

Keywords Irony $\cdot$ Post-dictatorship $\cdot$ Photography $\cdot$ Bolaño

Es interesante el modo en que Estrella distante (1996), la novela del chileno Roberto Bolaño, entra en tensión con el género policial y la literatura de postdictadura. Por un lado, nunca termina de ceñirse a las reglas de la novela negra

This article is part of the project The Politics of Irony in Contemporary Latin American Literature on Violence, funded by NWO (Nederlands Fonds voor Wetenschappelijk Onderzoek/The Netherlands Organisation for Scientific Research).

Gonzalo Maier

g.maier@let.ru.nl

1 Radboud Universiteit Nijmegen, Erasmusgebouw, Erasmusplein 1, 6525 HT Nijmegen, The Netherlands 
(De Rosso 2002; Oliver 2012) y, por otro, se escapa al común de los textos chilenos de postdictadura, pues utiliza la ironía para desconfiar de la memoria. Así, lejos de paradigmas como el testimonio o la derrota, la novela de Bolaño elucubra sobre el fantasmal destino de Carlos Wieder, un fotógrafo-asesino del que paradójicamente no hay fotografías que permitan su captura. En otras palabras, el texto critica las políticas de la memoria y los discursos construidos en torno a ella durante la transición chilena. La ironía en este escenario parece central, pues genera una distancia crítica que atraviesa la obra y que incluso es posible observar en el modo en que el narrador aborda las fotografías a las que hace referencia. En la novela se hace mención a más de treinta fotografías e imágenes, asunto que ya se ha estudiado parcialmente (De los Ríos 2007; Jennerjahn 2002), pero hasta el momento no se ha abordado la importancia de la ironía en esas imágenes. Por lo mismo, y atendiendo a estos espacios en blanco, analizaremos algunas de esas imágenes presentes en Estrella distante, pues creemos que no sólo permiten reflexionar sobre el papel de la ironía en torno a la postdictadura chilena, sino porque también dan luces respecto a cómo la memoria y el olvido entran en una tensión curiosa, en algún grado similar a lo sostiene Paul Ricoeur cuando escribre que el olvido bien podría ser la ironía de la memoria (413).

\section{Fotografía e ironía: algunos apuntes}

Roland Barthes en Cámara lúcida (1981) reflexiona sobre la naturaleza de la fotografía. Su meta, en el transcurso del ensayo, es averiguar por qué algunas fotografías lo emocionan y otras no. A grandes rasgos, para él la fotografía es "un médium capaz de traer a los muertos. Una alucinación falsa al nivel de la percepción, verdadera a nivel del tiempo" (Barthes 1981, 166), es decir, un artefacto donde lo que se ve no es, pero ha sido. Y para Barthes es ése, precisamente, el núcleo de la experiencia fotográfica: "la foto no rememora el pasado (...), sino es el testimonio de que lo que veo ha sido" (Barthes 1981, 122). Sería la confirmación última, la prueba irrefutable-_ver para creer”, decía Tomás el Apóstol frente a la resurrección de Cristo-de la veracidad de un hecho.

Además, toda fotografía funciona a dos niveles: en el del referente, en este caso, lo fotografiado-lo archivado, lo recordado-; pero también en el del soporte o la materialidad de la misma foto. En ese sentido, la polaroid de unas vacaciones en la playa, diría Barthes, adquiere su valor real en perspectiva, es decir, sólo "con la desaparición irreversible de su referente" (Barthes 1981, 19). En otras palabras, con la muerte. Y esa asociación, ese muerto eventual y potencial que encierra cada retrato, deja en evidencia la relación barthesiana entre fotografía y memoria. Barthes, hacia el final del libro, repara en un hecho crucial que Susan Sontag, un par de años antes en Sobre la fotografía (1975), ya había reconocido como "la ironía póstuma" (Sontag 1978, 104) de toda imagen fotográfica. La misma polaroid de una familia en la playa, que se toma como un recuerdo, como el testimonio de haber visto y de haber estado en ese lugar, es también un recuerdo de que morirán todos los que aparecen ahí retratados. Y aún más: que eventualmente serán recordados con esa foto. Que permanecerán en ella. Así la fotografía, para Sontag y Barthes, es 
también un dispositivo irónico que llama o evoca a la muerte cada vez que se busca perpetuar (fotográficamente) un momento.

Jacques Derrida, en "The Art of Memoires", escribía sobre la estrecha relación entre nombre y memoria, y cómo todo nombre permite recordar a la persona que lo ostentaba. En otras palabras, el primer peldaño de la memoria sería siempre el nombre. Si nos detenemos por un momento en la dictadura chilena, resulta interesante confrontar que la necesidad de un nombre para mantener la memoria, es equiparable a la necesidad de una imagen. Como en "la fotografía no hay signos, pero [sí] hay elementos retóricos (...) el estilo hace que la foto sea lenguaje" (Barthes 1981, 16). En ese sentido, las fotografías generalmente en blanco y negro de los detenidos desaparecidos, que las madres colgaban de sus pechos a modo de protesta, están cargadas de elementos retóricos que las convierten en un lenguaje y, aún más, en un lenguaje de la memoria. Es una forma de recordar y de evocar a los muertos como si esa foto fuera, tal como escribía Barthes, un médium o, ya pensando nuevamente en nombres_y como señala Derrida-, "lo que en nuestra tristeza llamamos la vida de Paul de Man es, para nuestra memoria, el momento cuando el mismo Paul de Man podía responder a su nombre, Paul de Man" (Derrida 1986, 48).

La razón de la fotografía convertida en lenguaje-acaso en nombre-es que la retórica de esas fotos radica tanto en la imagen del desaparecido, es decir, en su rostro, como en su puesta en escena. Barthes llama a lo fotografiado el spectrum o "el retorno de lo muerto" (Barthes 1981, 30), el fantasma. Un sintagma que tiene su raíz en el espectáculo (spectaculum). Una puesta en escena donde su valor radica en el testimonio. De ahí que en el momento en que las madres exhiben el rostro recortado de sus hijos, fuera de contexto y ampliado, en que lucen una fotografía de carnet — de algún modo la imagen oficial de ellos_- están construyendo una puesta en escena sobre la puesta en escena de la propia foto. El marco, su materialidad, se reconstituye a partir del cuerpo de las mujeres que enseñan las fotos de sus hijos. Ellas, como soporte de esas imágenes, pasan a formar parte de esa retórica. Ellas, con las fotos colgantes de sus hijos desparecidos, hacen que esas fotos sean un lenguaje, y particularmente un potente lenguaje político.

Barthes, pensando en sus fotografías preferidas, se pregunta qué es lo que lo emociona en esas imágenes. Qué es eso que lo perturba. A ese elemento, él lo llama punctum, precisamente porque actúa punzando, saliendo de la foto e interpelándolo como espectador. El punctum, en otras palabras, es lo que escapa de la imagen, y difiere del spectrum. Este último sería el tema de la foto, mientras que el punctum es el elemento difuso que no está en ella, que no es parte del referente fotografiado, pero que nosotros, como espectadores en la distancia, acaso en el futuro, sí podemos entrever. El ejemplo que da Barthes es sencillo. Una foto en blanco y negro de Lewis Payne, un condenado a muerte (Barthes 1981, 146). Sin ese dato sólo sería la foto de un hombre joven, tal vez un tipo serio y malhumorado, pero con el dato, que está fuera del marco, Barthes encuentra el punctum. Sólo entonces la fotografía lo interpela.

En el caso de las madres de detenidos desaparecidos, el fenómeno del punctum se da exactamente igual. Una fotografía en blanco y negro. Con un un rostro en primer plano que podría ser mil rostros, tal como en las obras del artista Eugenio Dittborn, 
pero nosotros sabemos que esa persona está desaparecida. Por eso, el punctum en las fotos de los detenidos desaparecidos remite literalmente a la definición de la fotografía que entrega Barthes: "esto ha sido" (Barthes 1981, 165). Y hay una foto, es decir, una certeza. Ellos efectivamente han sido y no están.

El asunto, por cierto, resulta central en Estrella distante, una novela narrada in extremis res por Arturo B, una suerte de alter ego del mismo Roberto Bolaño (Manzoni 2002). La historia comienza en Concepción, durante la Unidad Popular, cuando unos jóvenes aspirantes a escritores y artistas se reúnen en torno a un taller de poesía. A poco andar, sucede el golpe de Estado y uno de sus integrantes, Carlos Ruiz-Tagle_que a partir de ese momento pasa a ser conocido como Carlos Wieder-, asesina a dos mellizas que asistían a los talleres y luego fotografía sus cuerpos. Así, Wieder se revela en realidad como un piloto de la Fuerza Aérea con una monstruosa inquietud artística. Durante esos años, Wieder se hará famoso como poeta, será bendecido por el crítico de turno en los diarios nacionales y más tarde desaparecerá por completo, incluso sin dejar fotografías en las que se lo pueda reconocer con claridad. La novela, por cierto, seguirá las pesquisas y los recuerdos de Arturo B para finalmente descubrir cómo Wieder supuestamente viviría en un pueblo de la costa catalana.

Como veremos, tanto en las fotografías tomadas por Carlos Wieder como en las que supuestamente aparecería él, el punctum está en lo ausente, es decir, en aquello que queda fuera del marco. Esas imágenes paradójicamente apelan a la lógica de la ausencia y de la desaparición, que se contrapone a la memoria y al ánimo archivístico y documental que se le exigía a la fotografía durante la dictadura.

En la novela se hace mención a más de treinta fotografías, y la primera de todas ellas, casi en un gesto inaugural, está tomada por el mismo Carlos Wieder, cuando se hacía llamar Alberto Ruiz-Tagle, un joven que ostentaba un apellido emblemático de la élite chilena. La fotografía está tomada con la Leica de Wieder y en ella aparecen todos los jóvenes poetas que asistían a un taller literario en Concepción. Allí discutían "no sólo de poesía, sino de política, de viajes (que por entonces ninguno imaginaba que iban a ser lo que después fueron), de pintura, de arquitectura, de fotografía, de revolución y lucha armada" (1996, 13). Esa foto, que no se describe ni siquiera ecfrásticamente — es decir, representando verbalmente una imagen-y que de hecho se omite, se la conoce sólo por una referencia muy breve: "sobre una banqueta de madera [estaba] la Leica de Ruiz-Tagle, la misma que una tarde utilizó para sacarnos fotos a todos los miembros del taller de poesía" (1996, 19).

A propósito de las fotografías reconocidas generalmente como irónicas, Gregory Currie se pregunta si efectivamente lo son. Para eso toma como ejemplo la foto de una señalética pública que dice "No shooting”. La señal, eso sí, está en medio del campo y llena de orificios de bala. La ironía que supone esa fotografía, lógicamente, está dada por la prohibición de disparar y por los disparos que hay sobre esa misma imagen. Currie señala que una fotografía es irónica no en función de lo retratado, sino de la falta de independencia entre el referente y la fotografía (Currie 2011, 166). Es decir, puede que el referente, ya fuera del marco de la foto, no sea irónico, pero al enmarcarse efectivamente sí lo sea. Además, si la ironía es la tensión entre dos sentidos, no necesariamente opuestos pero sí distintos (Hutcheon 1994, 56), ella 
opera en este caso como una provocación, como un punctum del discurso que tensiona lo desconocido y lo conocido.

Entonces, con esa primera fotografía de Estrella distante, podemos reconocer que el punctum está fuera del marco: la imagen de esos poetas jóvenes que posan frente a la cámara como si fueran un souvenir resulta irónica sólo cuando el lector conoce la historia que viene después. Cuando se mira la fotografía en retrospectiva es cuando ella, según Barthes, cobra significado. Las fotos de esos poetas podrían incluso carecer de elementos irónicos-mal que mal las fotos no las vemos ni se nos describen-, pero nosotros sabemos efectivamente lo que sucederá más tarde: que muchos morirán, que vendrá el golpe de Estado, que otros se exiliarán, que quien les toma la foto es un oscuro poeta asesino (que ellos no serán capaces de reconocer ni encontrar), pero en ese momento, a comienzos de 1973, posan libremente para él. Se entregan a su lente. Se ofrecen como blancos para que Ruiz-Tagle dispare su Leica, acaso la más romántica y bohemia de todas las cámaras. Le ofrecen su imagen para que él, con la foto, las transforme en memoria. ${ }^{1}$ Wieder convierte esas fotografías, a fin de cuentas, en lo que para Susan Sontag eran precisamente las fotos, "un inventario de la mortalidad" (Sontag 1978, 105). Ese hecho, ajeno incluso al marco de la foto, su punctum, la resignifica y la transforma en una ironía del destino.

Ulrich Baer, escribiendo sobre la relación entre el trauma y la fotografía en Spectral Evidence: The Photography of Trauma (2002), sostiene que "las imágenes consideran preguntas abiertas no sobre su facticidad, sino sobre el modo en que algunos eventos adquieren sentido sólo en retrospectiva-o para usar un término freudiano, nachträglich, o tardíamente-y cómo ese registro tardío puede facilitar o bloquear el recuerdo" (Baer 2002, 181). Esa dimensión del trauma expuesta en la fotografía permite entender tal vez la distancia de Belano y su neutralidad al recordar esa primera foto (y las que vendrán después, por cierto). Así, la importancia y la fijación constante de un narrador respecto a la fotografía, podría leerse no sólo desde la memoria sino paradójicamente también desde el afán por olvidar, pues la relación entre memoria y olvido es parte de una dialéctica inevitable que, según Paul Ricoeur, está implícita en la misma naturaleza de cualquier recuerdo (Ricoeur 2006, 413).

\section{Las Garmendia: los cadáveres vivientes}

Fotográficamente, uno de los pasajes más interesantes de la novela es el del asesinato de las hermanas Garmendia, que a la vez es el crimen que echa a andar la leyenda en torno a Carlos Wieder, en ese entonces Alberto Ruiz-Tagle. Este último era una figura enigmática que asistía al taller de poesía de Juan Stein y del que se enamoró una de las hermanas Garmendia. Así, una noche tras el golpe de Estado,

\footnotetext{
1 Valeria de los Ríos en "Cartografía salvaje: mapa cognitivo y fotografías en la obra de Bolaño", repara en el modo en que la fotografía significó un adelanto técnico invalorable para la labor policial, ya que desde ese momento se podía identificar a los delincuentes con mayor celeridad y precisión. De esa concepción policial se desprende la aparición posterior de la fotografía en los archivos públicos y ciertas prácticas de espionaje (quizá un buen ejemplo sean los agentes de la CNI que durante las protestas contra la dictadura se disfrazaban de reporteros gráficos y fotografiaban a los manifestantes).
} 
Ruiz-Tagle las visita y ellas lo invitan a dormir pensando más en tenerlo cerca que en el toque de queda. "Unas horas después Alberto Ruiz-Tagle, aunque ya debería empezar a llamarle Carlos Wieder, se levanta" (1996, 31), escribe Arturo B, y las asesina.

Pese a que el lector no lo sabrá hasta el momento de la exposición fotográfica, Wieder no sólo les da muerte sino que además fotografía los cadáveres de las hermanas Garmendia, que permanecerán desaparecidas durante años. De hecho, mucho más tarde se encontrará un solo cuerpo "en una fosa común, el de Angélica Garmendia (...), pero únicamente ése, como para probar que Carlos Wieder es un hombre y no un dios" (1996, 33). Siguiendo las pautas de la Avanzada y cuestionando la lógica del apagón cultural, ${ }^{2}$ una de las primeras intervenciones artísticas de Wieder consistía en montar una exposición en un pequeño departamento que según él-y para usar su tono grandilocuente — no se limitaría sólo a la fotografía sino a la "poesía visual, experimental, quintaesenciada, arte puro" (1996, 87).

Eugenia Brito en Campos minados: la literatura post-golpe (1994) escribe que tras la irrupción militar "los lugares desde los cuales se habla son casas, departamentos y dentro de ellos, salones gastados, baños, eriales, oficinas desmobladas" (Brito 1994, 17). Los sitios públicos, según Brito, no serán habitables sino hasta después de casi una década. Y en ese espacio privado donde actuaba la primera Avanzada, donde se protegía el discurso del escrutinio oficial, es donde se sitúa el mismo Wieder. A él previamente le habían ofrecido un departamento completo para montar su exposición, pero "rechazó la propuesta. Argüyó que las fotos necesitaban un marco limitado y preciso como la habitación del autor" (1996, 87).

Considerando la misma dimensión espacial de ese montaje, aunque centrada en el análisis de "Ramírez Hoffman, el infame", ${ }^{3}$ Ina Jennerjahn lee esa decisión de Ramírez Hoffman/Wieder, contrapuesta a la magnanimidad del poema aéreo que esa misma mañana había escrito sin mucha suerte sobre los cielos lluviosos de Santiago, como una decisión eminentemente política destinada a invalidar el lenguaje de la resistencia: "Al realizar una exposición de arte en una casa privada, el protagonista se apropia de estrategias de los artistas opuestos al régimen

\footnotetext{
${ }^{2}$ A finales de la década de los 70 el término apagón cultural lógicamente hacía referencia a la escasa vida artística en Chile tras el golpe de Estado y estaba ampliamente extendido. En ese contexto, cierto grupo de escritores, poetas y artistas visuales, coincidieron en utilizar el cuerpo y la vía pública como espacio operativo. La lógica, según Nelly Richard, respondía a la necesidad de subvertir el lenguaje de la dictadura (Richard 1994, 118): si las exposiciones iban a ser clausuradas o visadas, la estrategia de estos artistas sería cuestionar el mismo concepto de arte que utilizaba la dictadura, ejecutando performances en sitios ajenos a la institucionalidad artística, que por su naturaleza no se volverían a repetir y que, por extensión, no podrían ser clausuradas, ampliando de ese modo "los soportes técnicos del arte al cuerpo vivo y a la ciudad" (Richard 2006, 104). En retrospectiva, este grupo de artistas fue bautizado por Nelly Richard, ciertamente la teórica de la cultura que los ha estudiado con mayor profundidad, como la Escena de Avanzada.

${ }^{3}$ La literatura nazi en América (1996), también de Roberto Bolaño, contiene un texto titulado "Ramírez Hoffman, el infame", donde en 23 páginas relata la historia de Ramírez Hoffman, un desaparecido piloto de la Fuerza Aérea chilena, que también fue un poeta con tendencias asesinas que contextualizaba sus crímenes con intertextos vanguardistas. En ese sentido, Estrella distante sería una ampliación de ese texto.
} 
dictatorial, quienes desde su extrema marginalización acudieron a formas alternativas de organizarse" (Jennerjahn 2002, 74). Una lectura de este tipo supone que el discurso de Wieder se explica, como hemos dicho, desde la Avanzada y no desde la mera vanguardia. Así aparecen las fotografías que Wieder le toma a las hermanas Garmendia y a otra serie de mujeres muertas. La falta de autonomía en los campos artísticos tras el golpe, permite comprender tanto la heterogeneidad de la Avanzada, como que un oficial de la Fuerza Aérea torture y luego escriba poemas con tintes bíblicos en los cielos de Santiago o en la Antártida, como si todo fuera parte de un mismo plan uniforme, como si la brutalidad de la dictadura permitiera con naturalidad este tipo de solapamientos.

El montaje fotográfico de Wieder se extiende durante varias páginas y es el teniente Julio Muñoz Cano, un antiguo oficial del ejército, quien lo expone con mayor detalle en un libro al que se refiere Belano titulado Con la soga al cuello:

Según Muñoz Cano, en algunas de las fotos reconoció a las hermanas Garmendia y a otros desaparecidos. La mayoría eran mujeres. El escenario de las fotos casi no variaba de una a otra por lo que deduce es el mismo lugar. Las mujeres parecen maniquíes, en algunos casos maniquíes desmembrados, destrozados, aunque Muñoz Cano no descarta que en un treinta por ciento de los casos estuvieran vivas en el momento de hacerles la instantánea (...). Las fotos, en general (según Muñoz Cano), son de mala calidad aunque la impresión que provocan en quienes las contemplan es vivísima. El orden en que están expuestas no es casual: siguen una línea, una argumentación, una historia (cronológica, espiritual...), un plan. Las que están pegadas en el cielorraso son semejantes (según Muñoz Cano) al infierno, pero un infierno vacío. Las que están pegadas (con chinchetas) en las cuatro esquinas semejan una epifanía. Una epifanía de la locura. En otros grupos de fotos predomina un tono elegiaco (¿pero cómo puede haber nostalgia y melancolía en esas fotos?, se pregunta Muñoz Cano) (...). La foto de la foto de una joven rubia que parece desvanecerse en el aire. La foto de un dedo cortado, tirado en el suelo gris, poroso, de cemento $(1996,97)$.

Roland Barthes, respecto al acto de fotografiar cadáveres, anota directamente que es una práctica horrible "porque certifica, por decirlo así, que el cadáver es algo viviente, en tanto cadáver: es la imagen viviente de una cosa muerta" (Barthes 1981, 118). Es decir, la brutalidad de esos retratos tomados por Wieder radica en el hecho de mantener, casi al modo de una ironía situacional, el estatuto viviente de las Garmendia cuando oficialmente son desaparecidas. De hecho, esas imágenes-para utilizar la jerga fotográfica- revelan dónde están las hermanas y qué sucedió con ellas. Esas fotos esconden el destino de las Garmendia y anulan la etiqueta de desaparecidas, pero lo hacen subvirtiendo la misma definición de la fotografía. Jennerjahn, a propósito de esa misma escena pero en La literatura nazi en América, apunta que "con su exposición de fotos, Ramírez Hoffman no solo subvierte la estrategia del secreto en que se basa la política de la desaparición. También pervierte las acciones de arte de la neovanguardia chilena, el gesto de protesta y denuncia que estas quisieron implicar" (Jennerjahn 2002, 81). Es decir, lo que hace Ramírez Hoffman/Wieder es quitar el velo sobre los comandos de la CNI o la DINA 
que detenían ilegalmente a personas en Chile, y mostrar lo que no se debía mostrar. Lo que era necesario mantener oculto bajo el velo de la propaganda y la higiene (Sepúlveda 2008, 69). Así, esas fotografías cumplen el rol primordial de toda imagen fotográfica: muestran y dan testimonio de lo que ha sido. Y dan testimonio, ciertamente, al modo del arte de la Avanzada, pero anulando irónicamente el propio lenguaje de la protesta. Utilizándolo para mostrar el horror y no para su denuncia.

$\mathrm{Si}$, como decíamos recién, las fotografías muestran lo que ha sido-y lo que ha sido no es sólo la muerte de las Garmendia, sino la condición torturadora del fotógrafo, o como dice Butler pensando en quienes fotografían este tipo de hechos, "el fotógrafo es parte de la tortura, es otro torturador" (Butler 2009, 138)—, en este caso el cuerpo mutilado, "la foto de un dedo cortado" (1996, 97), no sólo da testimonio de que las Garmendian han sido, sino de que su cuerpo como tal ya no existe. De ahora en adelante, y gracias a la memoria de esas imágenes, serán sólo partes de un cuerpo mutilado. Las fotografías, en algún sentido, les quitan el nombre a las Garmendia. Las despersonalizan. Desde este enfoque, esas fotos también pueden ser consideradas como el testimonio de una masacre que efectivamente $h a$ sido y no únicamente el testimonio de que las Garmendia han sido.

Esas fotografías, tomadas - para usar nuevamente la jerga fotográfica - a través del objetivo ${ }^{4}$ de Wieder, también se pueden leer al revés. Tal vez lo perturbador radica en que la memoria de las Garmendia permanecerá mutilada, ligada al horror de esa tortura. A propósito de este efecto, Barthes escribe que "la inmovilidad de la foto es como el resultado de una confusión perversa entre dos conceptos: lo Real y lo Viviente: atestiguando que el objeto ha sido real, la foto induce a creer que es viviente" (Barthes 1981, 118). Entonces, las imágenes repartidas en esa habitación hacen de las Garmendia dos muertas vivientes, al modo de zombies atrapados en esas instantáneas. De hecho, lo que hacen esas fotos es definir la vida de las Garmendia, tal como sucede en la novela, a partir de una fotografía. De esa descuartización. Cosa curiosa, cuando el mismo Belano elucubra y trata de adivinar cómo era la vida de los padres de las Garmendia, ya muertos, a partir de una fotografía de ellos que colgaba de alguna pared de la casa.

En Spectral Evidence: The Photography of Trauma, Baer se detiene en las fotos de Fou-Tchou-Li, un ciudadano chino que a comienzos de la década de 1930 fue condenado a morir por "La tortura de las cien piezas", y cuya ejecución fue detalladamente fotografiada y luego novelada por Salvador Elizondo. Al respecto, Baer sostiene que finalmente "las fotos de un hombre en un límite inconcebible expone a los espectadores a una visión que abre (...) preguntas complicadas sobre la fascinación social de la muerte como espectáculo" (Baer 2002, 183). Sobre el mismo fenómeno, Judith Butler sostiene la importancia del marco al momento de:

\footnotetext{
${ }^{4}$ Clément Rosset en L'École du réel (2008) repara precisamente en el término "objetivo", haciendo referencia a la mira a través de la que el fotógrafo, en las antiguas cámaras fotográficas, circunscribía el marco de la foto. Para él ese término-objetivo - hace alusión directa a la objetividad y supuesta fiabilidad que a fines del siglo XIX se le otorgaba a la fotografía (Rosset 2008, 431). En el caso de Wieder toma ribetes irónicos pues su objetivo fotográfico vale también como el objetivo militar (el blanco al que se dispara) y como lo objetivo, es decir, como la verdad instaurada desde la oficialidad de la dictadura.
} 
(...) establecer una relación entre el fotógrafo, la cámara y la escena. Las fotos describen o representan una escena, la imagen visual conservada dentro del marco fotográfico. Aunque la cámara está fuera del marco, se halla claramente "en" la escena como su exterior constitutivo. Cuando fotografiar estos actos de tortura se convierte en un tema de debate público, la escena de la fotografía se amplía. La escena se vuelve no sólo la localización espacial y el escenario social en la cárcel como tal, sino la esfera social entera en la que la foto es mostrada, vista, censurada, publicitada, comentada y debatida (Butler 2009, 117).

En Estrella distante la tortura aparece mediada a través de la fotografía tal como si ella fuera literalmente el marco ético, y es precisamente ese límite el que impide la locura, sostiene Barthes, la confusión total, el eventual riesgo siquiátrico. El marco de las fotos en donde aparecen las hermanas Garmendia descuartizadas vale, en algún sentido, como la mediatización que permite alejarse y recobrar esa tortura. Aunque también el tono del narrador y la constante asimilación de Wieder con el mal refuerzan esa idea. Así, rodeados de esas fronteras éticas-la ficcionalidad del marco y el discurso amnésico de Arturo B-, una lectura irónica pareciera ser posible sólo mediando los límites que otorgan un distanciamiento fotográfico-toda fotografía, en algún sentido, supone la distancia temporal, física y narrativa- y considerando la parodia tanto a la Avanzada como a los mecanismos de protesta contra el régimen. Por lo mismo, se puede leer irónicamente la relación entre la exposición fotográfica del piloto de la FACh y la Avanzada. O la ironía de Wieder al hacer que las desaparecidas pasen a ser automáticamente aparecidas, o que sus fotografías no sean las comunes y corrientes-las que le corresponden a las víctimas y que las madres colgaban de sus cuerpos-, sino otras catalogadas como artísticas. Wieder, entonces, gracias a la distancia mediada de la fotografía, juega con la tensión entre el horror y la denuncia, entre la estética de la vanguardia y la ética de los represores.

\section{Fotografías borrosas: la imagen de Wieder}

En "La proyección del secreto", Joaquín Manzi apunta que Estrella distante parece la ampliación, casi al modo de una fotografía, de "Ramírez Hoffman, el infame". Ya en ese capítulo, el aviador de la Fuerza Aérea chilena era conocido como "el fotógrafo de la muerte" (Bolaño 1996a, b, 94) por la violencia y el sadismo que encerraban sus obras, demostrando al mundo que "el nuevo régimen y el arte de vanguardia no estaban, ni mucho menos, reñidos" (Bolaño 1996a, b, 39). Como un fotógrafo y un agente de la muerte, Wieder parece teñir el argumento de Estrella distante con la sutil ironía del olvido cuando las fotos, precisamente, debieran traer el recuerdo y con él, las respuestas.

Respecto a Wieder, en la novela hay dos perspectivas fotográficas: las instantáneas que él toma-como aquella que daba inicio a la novela o la de las hermanas Garmendia - y la que le toman a él. Pues hay sólo un retrato suyo, que será crucial desde el inicio hasta el final de la historia. Esa foto aparece junto a una 
nota publicada en El Mercurio y está firmada por Nicasio Ibacache, "anticuario y católico de misa diaria aunque amigo personal de Neruda y antes de Huidobro y corresponsal de Gabriela Mistral y blanco predilecto de Pablo de Rokha y descubridor (según él) de Nicanor Parra" (1996, 45), es decir, haciendo referencia clara, como es sabido, a Ignacio Valente, el crítico central de la literatura chilena durante la segunda mitad del siglo XX, que en Nocturno de Chile (Bolaño 2000) aparecerá bajo el nombre de H. Ibacache.

En su artículo, el crítico lee la poesía de Wieder en clave católica, que fue más o menos la misma operación que en algún momento pretendió hacer Valente respecto a la poesía de Zurita (Valente 1982, E3). ${ }^{5}$ En cualquier caso, lo que nos interesa es que las dos fotografías que acompañaban a esa nota de prensa, no son un marco inocuo e indiferente. La imagen de Wieder viene desde la oficialidad de la crítica y los medios de comunicación. Aparece de algún modo visada por la dictadura, es una imagen oficial, casi al modo de la fotografía de un pasaporte, y como veremos, muy poco oficiosa:

En la primera se ve un avión, o tal vez sea una avioneta, y su piloto en medio de una pista que se adivina modesta y presumiblemente militar. La foto está tomada a cierta distancia por lo que las facciones de Wieder son borrosas. Viste chaqueta de cuero con cuello de piel, una gorra de plato de las Fuerzas Aéreas Chilenas, pantalones vaqueros y botas a tono con los pantalones. El titular de la foto reza: El teniente Carlos Wieder en el aeródromo de Los Muleros. En la segunda foto se observa, con más voluntad que claridad, algunos de los versos que el poeta escribiera sobre el cielo de Los Ángeles, después de la magna composición de la bandera chilena $(1996,46)$.

Es decir, de las dos fotos que aparecen en el reportaje, sólo en una es posible distinguir a Wieder, aunque pocas páginas más adelante se lee "dos días después la Gorda llamó a Bibiano y le dijo que Alberto Ruiz-Tagle era Carlos Wieder. Lo había reconocido por la foto de El Mercurio. Cosa bastante improbable, como me hizo notar Bibiano, semanas o meses después, puesto que la foto era borrosa y poco fiable" (1996, 51).

La leyenda de Wieder, de este modo, se construye sobre esa falta de certezas, sobre su invisibilidad fantasmagórica. Por eso la ironía de la única foto fiable de Wieder es radical. Ella tiene la misión de individualizar al poeta y al culpable, pero no hace más que lo contrario: sitúa a Wieder del lado de la desaparición y del enigma. Del lado, irónicamente, de los desaparecidos. La foto no muestra a Wieder sino un espacio vacío, por rellenar, una interpelación para que incluso quienes lo conocían tuvieran que completar lo que faltaba en esa imagen: “¿En qué se basaba la Gorda para su identificación? En un séptimo sentido, me parece, dijo Bibiano, ella cree reconocer a Ruiz-Tagle por la postura" $(1996,52)$.

La fotografía, ya lo advertía Barthes, es en esencia invisible ya que sólo deja ver lo retratado, es decir, remite directamente al referente. $\mathrm{Y}$ en este caso, la invisibilidad de la foto es doble porque el lector de la novela lógicamente no puede

\footnotetext{
5 Para más detalles sobre la relación entre Wieder y Zurita consultar: "Roberto Bolaño y Raú 1 Zurita: referencias cruzadas", de C. Bolognese (2010).
} 
ver la fotografía-sólo se describe- - y Wieder tampoco es reconocible en ella. Lo que hace esa fotografía-y esta ironía dramática sólo la pueden entender los lectores en perspectiva - no es develar sino oscurecer la posibilidad de encontrar en el futuro a Wieder. La foto, por lo tanto, que debía mostrar a un gran poeta en ciernes, será finalmente uno de los grandes velos que ocultará al asesino. ${ }^{6}$

Desde un comienzo se ha leído la obra de Bolaño centrando el análisis en la idea de mal como el gran articulador de sus ficciones (Candia 2010). En este caso, el mal encarnado en el fascismo de una dictadura latinoamericana y, en particular, en uno de sus artistas. La concepción clásica de mal-aristotélico-tomista, realmente-, entendida como la ausencia del bien, también da luces sobre la única fotografía de Wieder. De hecho, parafraseando esta definición de mal, la foto de Wieder es la propia ausencia de la foto. Inquieta (hace punctum) precisamente porque no termina de aparecer, porque pone en entredicho la capacidad archivadora de la misma fotografía. Esa imagen publicada en El Mercurio terminará recordando no al poeta asesino, sino la ironía que dejan los espacios vacíos en un contexto dictatorial, donde tanto a la fotografía como a la memoria se le exigía expresamente su misión más básica: archivar.

Respecto al modo en que opera la memoria, en "The Art of Memoires", Derrida distingue la Mnemosyne de la Lethe. Es decir, marca una frontera entre lo recordado y lo olvidado. La memoria (Mnemosyne) operaría eminentemente bajo paradigmas alegóricos, mientras que el olvido (Lethe) sería para él la ironía de esa memoria (Derrida 1986, 84). Y el olvido en las fotografías descritas en la novela (o la incapacidad de retener a Wieder) parece ser el punctum. Lo que inquieta. Para Paul Ricoeur, "el olvido es el desafío por excelencia para probar la fiabilidad de la memoria. La honradez de los recuerdos llevan al enigma constitutivo de morir, es decir, la dialéctica entre la presencia y la ausencia de representaciones del pasado" (Ricoeur 2006, 414). Una dialéctica que se podría relacionar directamente con la fotografía y el encuadre, con la voluntad de dejar fuera o dentro del marco, pues al igual que con los recuerdos es imposible utilizar la estrategia de Funes, el memorioso, y fotografiarlo todo.

Y es precisamente Wieder, el artista-asesino al que nadie le puede seguir el rastro, quien opera bajo el paradigma del olvido. Todo lo que rodea a Wieder-y he aquí la más grande ironía situacional o dramática de la novela- es el olvido y nada más que el olvido. De hecho, esa ironía se extenderá por los capítulos y determinará el argumento completo de la novela, transformándose, al decir de Pierre Schoentjes, en una ironía narrativa (Schoentjes 2001, 52), donde la tensión entre lo que se olvida y lo que se recuerda definirá completamente los acontecimientos y la historia narrada, en este caso, por Arturo B.

Visto de otro modo, lo que interpela de esa imagen publicada en El Mercurio es cómo Wieder, durante toda la novela, no tiene un rostro, sino muchos, casi tantos como los que aparecen en las obras de Dittborn, donde las imágenes se mezclan y

\footnotetext{
${ }^{6}$ Ya sobre otro ámbito de la obra de Bolaño, Valeria de los Ríos escribe: "La fotografía como identificación-o como ausencia de esta - se encuentra también inscrita en las víctimas a los asesinatos de 2666. Aquí la fotografía es puesta directamente en manos de policías, detectives, o publicada en la prensa, como forma de ubicar a personas desaparecidas o para reconocer-muchas veces sin éxito-a las víctimas" (de los Ríos 2007, 76).
} 
confunden ajenas a cualquier voluntad de nombrarlas o individualizarlas. Wieder, de hecho, tampoco tiene sólo un nombre (Ruiz-Tagle, Wieder, R.P. English ${ }^{7}$ ) y se lo sigue de país en país (Chile, Francia, Inglaterra, España). Y ese anonimato, propio del olvido, de la falta de culpabilidad y de la lógica contra la que luchaba la Avanzada, es el que en las páginas siguientes pareciera seguir encarnando Wieder.

Una vez Bibiano me enseñó una foto: ésta era mucho mejor que aquella en la que la Gorda creyó reconocer a Ruiz-Tagle. En efecto, Wieder y Ruiz-Tagle se parecían, pero yo por entonces en lo único en que pensaba era en abandonar el país. Lo cierto es que, tanto en la foto como en las declaraciones, ya no quedaba nada de aquel Ruiz-Tagle tan ponderado, tan mesurado, tan encantadoramente inseguro (incluso tan autodidacta). Wieder era la seguridad y la audacia personificadas $(1996,53)$.

Este comentario de Belano parece fundamental para entender la relación entre memoria y fotografía. Incluso ante la posibilidad de que una mejor foto permita identificar a Wieder, el narrador se muestra indiferente. Es como si incluso una buena fotografía (una imagen clara, archivadora, es decir, con memoria) fuera incapaz de identificarlo, poniendo de manifiesto que la memoria de Wieder no está anclada en imágenes. $\mathrm{O}$ bien, que Wieder debe ser entendido desde la ausencia o la ironía de la memoria.

De todas las referencias cinematográficas presentes en la novela, hay una que llama particularmente la atención. Es cuando Bibiano visita el departamento de Wieder y le relata a Belano que "se había sentido como Mia Farrow en El bebé de Rosemary, cuando va por primera vez, con John Cassavettes, a la casa de sus vecinos. Faltaba algo. En la casa de la película de Polanski lo que faltaba eran los cuadros (...). En la casa de Ruiz-Tagle lo que faltaba era algo innombrable" (1996, 17). Ese pasaje donde lo irreproducible se condice con lo enigmático, opera precisamente bajo la misma lógica. Lo ausente, tal como el mal respecto al bien, son los cuadros. Y en el caso de Estrella distante lo ausente, es decir el mal, es la historia del propio Wieder, un fotógrafo que irónicamente no propicia la memoria sino un olvido radical.

En algún sentido, la culpabilidad de Wieder aumenta en la medida en que el enigma en torno a él está dado por la ausencia. Él no está retratado y sus imágenes son difusas. Una operación así afirma por negación que lo contrario al enigma y al mal es lo que se ve. Lo lúcido de la fotografía, como escribía Barthes, su capacidad de decir la verdad. De hecho, casi como asumiendo la derrota que encerraba el intento por interceptar a Wieder, el narrador dice que incluso "algunos entusiastas salen al mundo dispuestos a encontrarlo y, si no a traerlo de vuelta a Chile, al menos

\footnotetext{
7 Según el detective Abel Romero, Wieder también sería un fotógrafo de películas pornográficas llamado R.P. English. Su historia, además, se desarrolla en el cuento "Joanna Silvestri", incluido en el volumen Llamadas telefónicas (1997). En él, una actriz porno entrevistada por un detective chileno intenta recordar sin éxito a un antiguo camarógrafo, llamado R.P. English, del que guarda sólo una fotografía ("la foto que me enseña del presunto English es vieja y borrosa" [Bolaño 1997, 173]). La tensión que existe en Estrella distante entre la ausencia y la presencia de las fotografías, de algún modo se repite en la historia de Silvestri, quien recuerda lo filmado por English, pero no logra recordarlo a él ("su rostro ya hace mucho se instaló en la zona de las sombras” [Bolaño 1997, 173], dice).
} 
a hacerse una foto con él" (1996, 116), como si esa foto fuera capaz de revelar algo, de hacerlo presente, de demostrar de una vez por todas que Wieder no era sólo un espejismo.

Ya hacia el final de novela, cuando Romero, el genio detectivesco caído al olvido, inicia sus pesquisas lo hace coincidentemente con la misma fotografía de Wieder publicada hace ya más de 20 años en El Mercurio.

¿English era Wieder? Cuando Romero comenzó su investigación así lo creía y durante un tiempo recorrió Italia buscando gente que hubiera conocido a English a las que mostraba una vieja foto de Wieder (aquella en la que Wieder posa junto a su avión), pero no encontró a nadie que recordara al cámara, como si éste no hubiera existido o no tuviera rostro para ser recordado $(1996,134)$.

Nuevamente la ironía de la foto de Wieder, que estaba destinada a retratarlo, radica en que décadas después se sigue mostrando inútil y, sobre todo, única. Pero ya sabemos que además de la imagen borrosa de un joven Wieder, lo que muestra esa foto, el punctum, es el triunfo del olvido. El fracaso de la memoria, al menos en la historia reciente de Chile, y de la fotografía como el arma destinada a recordar.

El olvido para Paul Ricoeur "se experimenta como un ataque sobre la fiabilidad de la memoria. Un ataque, una debilidad, una laguna. En este sentido, la memoria se define a sí misma, al menos en primera instancia, como una lucha contra el olvido" (Ricoeur 2006, 413), una tarea que en el caso de Estrella distante opera en varios niveles, pero que encuentra en la única imagen de Wieder y en su inutilidad un ejemplo concreto de cómo la fotografía - sin mucha suerte- está llamada a sostener dentro de la novela la memoria, es decir, lo que ha sido.

\section{Conclusiones}

Estrella distante, como una novela de postdictadura, tensiona la relación entre horror y memoria básicamente a través de la búsqueda de Carlos Wieder, el asesino impune que desaparece y se transforma en un mito tanto de la poesía como de la dictadura chilena. El análisis se enfocó en algunas fotografías descritas en la novela que pueden ser leídas de un modo irónico y, más en particular, como una ironía dramática sobre lo que se recuerda y lo que se olvida. Esas fotografías-pero también otras, como la imagen de Allende entregándole una medalla al detective Romero, que este último perdió y le impide comprobar que era efectivamente un gran policía; o la imagen del General Cherniakovski, el único general judío del ejército ruso en la Segunda Guerra Mundial, que Juan Stein exhibía en su casa sin saber por qué- pese a su ánimo archivador y memorialístico, están rodeadas de olvido y, por extensión, de misterio. Las imágenes de Wieder, por ejemplo, son tan borrosas que no permiten identificarlo; las de las hermanas Garmendia mantienen vivas a las muertas, casi como si fueran zombis y no pudieran dejar de morir; la primera foto grupal del taller de poesía está perdida y en ella queda fuera precisamente Wieder, a quien más tarde no podrán identificar.

Está tensión entre lo que está y lo que no está conviene leerla en relación con la concepción de Barthes sobre la fotografía y, en particular, con el contexto de 
postdictadura en que los detenidos desaparecidos jugaron un rol central. Ellos también comparten el escenario fantasmagórico que combina lo ausente y lo presente, permitiendo leer en las fotografías de Estrella distante una crítica hacia las políticas de los primeros años de transición y, en particular, al papel de la justicia. Es precisamente el detective Romero quien aparece en las últimas páginas para hacer justicia paradójicamente fuera del aparato de justicia. La labor se vuelve difícil, claro, pues no hay imágenes que permitan reconocer a Wieder-o las que hay no son fiables- y, por lo mismo, requiere de la ayuda de un testigo, es decir, de Arturo B.

En este sentido, las fotografías presentes en Estrella distante ayudan a evitar el monumento y, en particular, el documento (Richard 2000, 11-12). Más que archivar y dar testimonio de lo que ha sido, dan cuenta de la imposibilidad de ese testimonio. La opacidad y la escasa fiabilidad de las imágenes valen como una ironía que apunta a los discursos tan propios de la transición centrados en la transacción (Richard 1998, 27), y la política de los acuerdos.

Open Access This article is distributed under the terms of the Creative Commons Attribution 4.0 International License (http://creativecommons.org/licenses/by/4.0/), which permits unrestricted use, distribution, and reproduction in any medium, provided you give appropriate credit to the original author(s) and the source, provide a link to the Creative Commons license, and indicate if changes were made.

\section{References}

Baer, U. (2002). Spectral evidence: The photography of trauma. Cambridge: MIT Press.

Barthes, R. (1981). Cámara lúcida. Trad. Joaquín Sala. Barcelona: Paidós.

Bolaño, R. (1996a). Estrella distante. Barcelona: Anagrama.

Bolaño, R. (1996b). La literatura nazi en América. Barcelona: Seix Barral.

Bolaño, R. (1997). Llamadas telefónicas. Barcelona: Anagrama.

Bolaño, R. (2000). Nocturno de Chile. Barcelona: Anagrama.

Bolognese, C. (2010). Roberto Bolaño y Raúl Zurita: referencias cruzadas. Anales de literatura chilena, $11,259-272$.

Brito, E. (1994). Campos minados: la literatura post-golpe. Santiago: Cuarto Propio.

Butler, J. (2009). Marcos de guerra: las vidas lloradas. Trad. B. Moreno. Barcelona: Paidós. 2010.

Candia, A. (2010). Todos los males el mal. La 'estética de la aniquilación' en la narrativa de Roberto Bolaño. Revista Chilena de Literatura, 76, 47-70.

Currie, G. (2011). The irony in pictures. British Journal of Aesthetics, 51, 149-167.

De los Ríos, V. (2007). Cartografía salvaje: Mapa cognitivo y fotografías en la obra de Bolaño. Taller de Letras, 41, 69-81.

De Rosso, E. (2002). Una lectura conjetural. Roberto Bolaño y el relato policial. In C. Manzoni (Ed.). Roberto Bolaño: la escritura como tauromaquia (pp. 133-143). Buenos Aires: Corregidor.

Derrida, J. (1986). The Art of Memoires. En Memoires for Paul de Man. transl. Cecile Lindsay et al. New York: Columbia UP, 47-88.

Hutcheon, L. (1994). Irony's edge. Nueva York: Routledge.

Jennerjahn, I. (2002). Escritos en los cielos y fotografías del infierno. Las 'Acciones de arte' de Carlos Ramírez Hoffman, según Roberto Bolaño. Revista de Crítica Latinoamericana, 56, 69-86.

Manzi, J. (2005). La proyección del secreto. Imagen y enigma en la obra de Roberto Bolaño. In F. Moreno (Ed.), Roberto Bolaño. Una literatura infinita (pp. 69-86). Poitiers: Université de PoitiersCNRS.

Manzoni, C. (2002). Narrar lo inefable. El juego del doble y los desplazamientos en Estrella distante. In C. Manzoni, (Ed.), Roberto Bolaño: la escritura como tauromaquia (pp.39-50). Corregidor: Buenos Aires. 
Oliver, M. (2012). Digresión y subversión del género policial en Estrella distante de Roberto Bolaño. Acta literaria, 44, 35-51.

Richard, N. (1994). La insubordinación de los signos. Santiago: Cuarto Propio.

Richard, N. (1998). Residuos y metáforas. Santiago: Cuarto propio.

Richard, N. (2000). Presentación. In N. Richard (Ed.), Políticas y estéticas de la memoria. Santiago: Cuarto propio.

Richard, N. (2006). La Escena de Avanzada y su contexto histórico social. In G. Mosquera (Ed.), Copiar el Edén. Arte reciente en Chile (pp. 103-120). Santiago: Editorial Puro Chile.

Richard, N. (n.d.). Lo político en el arte: arte, política e instituciones. http://hemisphericinstitute.org/ hemi/es/e-misferica-62/richard. Consultado el 07 de julio de 2015.

Ricoeur, P. (2006). Memory, history, forgetting. Chicago: Chicago UP.

Rosset, C. (2008). L'école du réel. Paris: Les Éditions de Minuit.

Schoentjes, P. (2001). Poétique de l'ironie. Paris: Éditions du Seuil.

Sepúlveda, M. (2008). Metáforas de la higiene y la iluminación en la ciudad poetizada bajo el Chile autoritario. Acta literaria, 37, 67-80.

Sontag, S. (1978). Sobre la fotografía. Trad. C. Gardini. Ciudad de México: Alfaguara. 2006.

Valente, I. (1982). "Zurita entre los grandes". El Mercurio 24 oct, E3. 